\title{
¿Se puede determinar el grado de gramaticalización de los marcadores del discurso a través de la prosodia? Un estudio preliminar
}

\author{
CAN PROSODY DETERMINE THE DEGREE OF GRAMMATICALIZATION OF DISCOURSE \\ MARKERS? A PRELIMINARY STUDY
}

\section{Maria Estellés Arguedas}

Universitat de València- Val.Es.Co.

Resumen

Una de las características atribuidas generalmente a los procesos de gramaticalización es la atrición o reducción fónica, que se incrementa a medida que el proceso de gramaticalización se encuentra más avanzado; así pues, ante una misma forma, las variantes más gramaticalizadas son más átonas que sus contrapartidas léxicas. En el caso de los marcadores y partículas discursivas, la atrición no es una característica frecuente, pero sí que se ha documentado una pérdida de sustancia fónica particular, concretamente en su configuración prosódica. A partir del estudio de dos marcadores del español bien estudiados diacrónicamente, encima y o sea, el presente artículo pretende comprobar si los valores que han sido datados como más gramaticalizados muestran, según lo esperable, un mayor debilitamiento prosódico. Para ello, se ha creado una base de datos a partir de corpus orales multigenéricos del español y se han analizado las muestras mediante software de análisis fónico.

Palabras clave: marcadores del discurso, gramaticalización, prosodia, corpus orales.
Abstract

One of the characteristics generally attributed to the processes of grammaticalization is attrition or phonic reduction. This reduction increases as the grammaticalization process advances, being the more grammaticalized variants generally more unstressed than their lexical counterparts. In the case of discourse markers and particles, attrition is not as frequent a feature, but a particular loss of phonic substance has been attested, related to its prosodic configuration. The present paper aims to check if the latter phenomenon applies to Spanish, i.e. if the more grammaticalized values of discourse markers show a greater prosodic weakening. To do so, two Spanish discourse markers, encima and o sea, both well studied diachronically, have been considered. For this purpose, a database was created with examples from oral corpora belonging to different genres; the samples have been analyzed using phonic analysis software.

Keywords: discourse markers, grammaticalization, prosody, oral corpora 


\section{INTRODUCCIÓN ${ }^{1}$}

Wichmann (2011), en el Oxford Handbook of Gramaticalization, dedica un capítulo a un aspecto hasta entonces poco estudiado de la gramaticalización: sus implicaciones prosódicas. La relación entre las características fónicas y el grado de gramaticalización de los elementos es una constante en prácticamente todos los trabajos sobre gramaticalización, independientemente de la perspectiva adoptada sobre este fenómeno; sin embargo, como Wichmann (2011) señala, casi todos se refieren únicamente al plano segmental, por cuanto se ocupan de la pérdida de sustancia fónica, es decir, de sonidos, que puede desembocar en última instancia en la reducción de fonemas. Este es el caso de ejemplos paradigmáticos de gramaticalización, como el paso de going to> gonna, o de INFINITIVO + habeo > INFINITIVO+-é. Sin embargo, Wichmann reivindica el papel del plano suprasegmental como el lugar primario del cambio fónico; en otras palabras, considera que, tras una pérdida de prominencia prosódica, y solo como consecuencia de esta, se produce una pérdida de sonidos, una relajación articulatoria de la secuencia que experimenta la gramaticalización. Esta pérdida de prominencia prosódica va asociada, en líneas generales, a la desacentuación. Así, la primera erosión que se produciría sería la prosódica, y esta desembocaría (no siempre y no necesariamente) en una pérdida fonemática.

La ventaja que tiene este postulado para quienes estudian la diacronía de los marcadores del discurso (MD) es que se podría rastrear el pasado de determinados elementos a partir de su prosodia; esto es, mediante un análisis prosódico de corpus orales actuales, se podría determinar qué elementos están más gramaticalizados y cuáles lo están menos y, por tanto, establecer qué valores surgieron primero y cuáles después. Sin esta afirmación sobre la prosodia, la posibilidad de estudiar la evolución de los MD por medio del componente fónico, como herramienta teórica subsidiaria, resulta en gran medida inviable: los MD en general tienen poca reducción fónica, al menos en comparación con categorías gramaticales como preposiciones, conjunciones, artículos, etc. Sin embargo, la posibilidad abierta por Wichmann es atractiva por cuanto, en teoría, aquellos ejemplos de MD cuya prosodia sea menos prominente serían los más gramaticalizados, los valores más modernos; en cambio, por ejemplo, cuanto más próximos en el tiempo estén a las construcciones de las que proceden, su prominencia prosódica, en teoría, aumentaría.

Esta herramienta subsidiaria no sería necesaria para casos en los que existen testimonios escritos recogidos en corpus, que dan cuenta de su historia; sin embargo, un caso especial lo constituyen un tipo particular de marcadores del discurso; se trata de los denominados, entre muchos otros nombres, marcadores conversacionales (Martín Zorraquino y Portolés 1999), aquellos MD más ligados a los géneros conversacionales, a la transmisión por vía oral y al registro informal de la lengua; es decir, elementos íntimamente vinculados a la

\footnotetext{
${ }^{1}$ La investigación conducente a este artículo ha sido financiada por el MINECO a través del proyecto La atenuación pragmática en su variación genérica: géneros discursivos escritos y orales en el español de España y América, (ES.VAG.ATENUACIÓN, código FFI2016-75249-P).
} 
interacción in praesentia y, por ende, poco representados en los testimonios escritos que se recogen en los corpus diacrónicos.

En las líneas siguientes, se testará esta posibilidad en encima y o sea, dos MD del español cuya evolución histórica ha sido bien trazada en trabajos previos, analizando su comportamiento prosódico. A partir de los valores que se les reconocen y del orden en que surgieron, se comprobará en un corpus oral contemporáneo si, en efecto, los casos de menor prominencia fónica se corresponden con los valores más gramaticalizados y viceversa. Antes, estableceremos qué se entiende específicamente por prominencia fónica y cómo se ha analizado en el corpus.

\section{LA PROSODIA Y LA GRAMATICALIZACIÓN DE LOS MMDD}

Como se avanzaba anteriormente, Wichmann (2011) o Dehé y Stathi (2012) señalan cómo, desde los inicios de los estudios de gramaticalización, casi todos los trabajos han señalado el carácter fónico de algunos de los cambios asociados al macroproceso de la gramaticalización. Se ha hablado de erosión, atrición, pérdida de sustancia fónica, relajación articulatoria, etc., pero son más escasas las obras que abordan la dimensión prosódica de este cambio. Además de la propuesta de Wichmann (2011), otros estudios como los de Dér (2013) se ocupan de este componente suprasegmental. También adoptan una perspectiva prosódica estudios particulares como los de Sohn (2010), para el coreano, o Dehé y Stathi (2012) y Wichmann et álii (2010), para el inglés.

La base de trabajos como los anteriores es que se podría trazar la evolución prosódica de los elementos gracias al análisis fónico de textos sincrónicos; en ellos, se puede comprobar cómo existe una tendencia, por parte de los elementos gramaticales, a presentar atonicidad, frente a sus contrapartidas léxicas, no gramaticalizadas, que suelen ser tónicas.

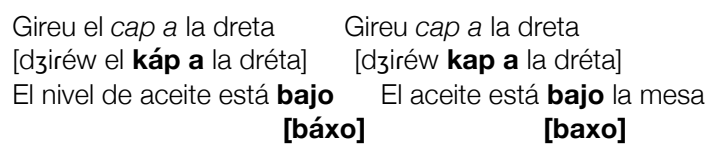

Esta circunstancia, confirmada por numerosos ejemplos de palabras indiscutidamente gramaticales (preposiciones, artículos, conjunciones, clíticos o afijos), se extiende también, según Wichmann (2011), al terreno de los MD. Para estos elementos, que voluntaria o involuntariamente centran su atención en el capítulo mencionado, la autora establece unos parámetros paradigmáticos y sintagmáticos sobre lo que considera disminución de la prominencia prosódica. En el plano paradigmático, se trata, como hemos dicho, de la destonicidad; esto es, un elemento o construcción que se pronunciaba tónico pasa a ser átono (deja de albergar un grupo acentual (cf. Garrido 2012) y, como consecuencia de ello, pasa a depender del grupo acentual anterior (como sílabas postónicas) o del posterior (como pretónicas). Esto, en términos prosódicos, supone una subordinación fónica. Del mismo modo, en el plano sintagmático considera que el elemento pierde independencia con respecto a los elementos que lo rodean. Esto es, comienza a desprenderse de las fronteras tonales y se integra en GE adyacentes. De modo que, prototípicamente, los MD son elementos átonos y prosódicamente integrados en grupos (acentuales y entonativos) más amplios. 


\section{normas}

¿Se puede determinar el grado de gramaticalización de los marcadores del discurso a través de la prosodia? | Maria Estellés

Estas constataciones anteriores pueden resultar chocantes a quienes se dedican al estudio de los MD, puesto que parecen contradecir (y Wichmann se hace eco de la controversia) las definiciones más establecidas de MD, tanto en el plano anglosajón (Schiffrin 1987) como en el hispánico. Así, Martín Zorraquino y Portolés (1999: 4064) señalan que los marcadores del discurso:

se encuentran limitados como incisos por la entonación. En una pronunciación esmerada, se percibe una pausa posterior al marcador y, a veces, también una anterior.

La creencia de que los MD tienen prototípicamente independencia prosódica y tonicidad es, para Wichmann (2011), demostrablemente errónea, a la luz de trabajos que señalan cómo son más frecuentes los casos en los que un MD aparece sin acento que aquellos en los que sí. Por supuesto, es posible encontrar un MD tónico o formando un grupo entonativo (GE) independiente, pero dada su menor incidencia en corpus, la autora considera que, cuando se da este caso, puede atribuirse a un caso particular de foco prosódico que - entendemos - responde a necesidades expresivas contextuales, particulares, y que por tanto no debe entenderse como la configuración fónica por defecto de los MD.

Como prueba de esta afirmación, la autora cita estudios como Hirschberg y Litman (1993) sobre now, o Wichmann, Aijmer y Simon-Vandenbergen (2010), para of course. En ambos casos, los significados más modernos y gramaticalizados se encuentran prosódicamente más integrados que los que lo están menos; es el caso del now adverbial (tónico) y del of course epistémico, frente a sus correspondientes más gramaticalizados, como MD el primero y como marca de common ground, el segundo. La autora cita también un trabajo propio (Wichmann 2009) sobre sorry, entre cuyos valores está el denominado 'trouble marker', tal como ilustran ejemplos como Say that again sorry o Sorry what did you say? (Wichmann 2011). Este valor de sorry, considerado cercano a la marcación del discurso (pragmatic particle) es, en sus palabras, "prosodically the least salient": se suele manifestar sin acento y es más breve que los otros valores registrados. MD. Más allá del caso del inglés, recoge el caso de enfin en francés, cuyo valor como partícula, derivado de su uso sintetizante, sirve como estrategia reparadora para interrumpir el propio mensaje y como un medio para interrumpir el de otros; así sucede en Enfin! Ça va pas, ça (Wichmann 2011); la autora, basándose en estudios específicos sobre la partícula, señala que este valor como partícula es, de nuevo, el más breve, y el menos prominente tonalmente.

Para la autora, la confusión procede probablemente de equiparar la sintaxis con la prosodia. De hecho, sugiere que el aumento de ámbito propuesto por la gramaticalización (desde Traugott 1995 hasta Tabor y Traugott 1998) para la evoclución de los MD (y de los elementos discursivos en general) no se corresponde con un aumento de ámbito prosódico, sino precisamente con lo contrario: con una reducción del ámbito prosódico, que lleva al elemento o construcción afectado a integrarse prosódicamente cada vez más, a medida que sintácticamente se va desgajando. Así, se entendería que el carácter parentético atribuido a estos elementos debe ser concebido únicamente en términos sintácticos o informativos.

\footnotetext{
+gramaticalización --> + dependencia prosódica (acentual y tonal)

+gramaticalización --> + independencia sintáctica
} 


\section{normas}

¿Se puede determinar el grado de gramaticalización de los marcadores del discurso a través de la prosodia? | Maria Estellés

En resumen, si los signos de una creciente dependencia prosódica indican una creciente gramaticalización, el siguiente paso sería localizar en un corpus oral los elementos con funcionamiento en el plano discursivo y comprobar cuál es su grado de dependencia prosódica (y, si la hubiera, de erosión fónica). Al menos en teoría - repetimos-, ello nos ayudaría a establecer cuáles son los valores más recientes y gramaticalizados de algunos MD cuya historia no ha quedado (suficientemente) registrada en corpus escritos.

Para ello, a partir de dos MD bien estudiados históricamente - para cuyas etapas se han establecido fechas fiables de surgimiento-, se comprobará en un corpus oral contemporáneo si sus valores, desde los más antiguos a los más modernos, siguen la progresión apuntada por Wichmann. La elección de los marcadores y la configuración del corpus se explicarán a continuación.

\section{ANÁLISIS DE CORPUS}

\subsection{La elección de los marcadores del discurso: o sea y encima}

Para comprobar la rentabilidad de la hipótesis en el caso del español, se han seleccionado dos MD en concreto, o sea y encima, puesto que ambos cumplen una serie de requisitos que resultan favorables para el análisis:

a) Son dos MD cuya historia ha sido profusamente analizada. Para el caso de encima, destacan entre otros los estudios de Garachana (2008), en cuya clasificación nos basaremos, y Azofra (2012); en cuanto a o sea, su historia queda trazada en Pons Bordería (2014). Se partirá del establecimiento de sus valores y el orden de aparición de sus valores propuesto en estas obras.

b) Ambos MD tienen presencia en el registro oral. Con algunas diferencias particulares que se tratarán en los apartados correspondientes, se pueden encontrar ejemplos de encima y o sea en discurso oral con una frecuencia de aparición importante, suficiente como para proporcionar una idea del comportamiento de sus valores. Ambos, además, son más frecuentes en registros orales. Como se verá a continuación, se ha puesto un énfasis especial en los ejemplos pertenecientes a este registro, puesto que en él se contienen todos sus significados, mientras que los registros más formales solo presentan algunos de ellos.

c) Pertenecen a dos tipos distintos de MD. Mientras que encima es considerado un conector aditivo, o sea se cataloga como reformulador explicativo (Martín Zorraquino y Portolés, 1999). De ese modo, trata de eliminarse una posible adscripción del patrón prosódico al tipo de instrucción codificada por el marcador.

Los valores particulares atribuidos a cada MD así como la evolución histórica y su orden de aparición se proporcionarán en el apartado 4.

\subsection{Selección de corpus y metodología de análisis}

Los dos MD seleccionados, encima y o sea, se han rastreado en un corpus propio compilado a partir de dos grandes corpus. Por un lado, el corpus Val.Es.Co. 2.0 (Cabedo 


\section{normas}

¿Se puede determinar el grado de gramaticalización de los marcadores del discurso a través de la prosodia? | Maria Estellés

\& Pons 2013), que ha constituido la fuente fundamental, y, por otro, parte del corpus CORLEC (Marcos Marín 1992). El primero recoge un total aproximado de 150.000 palabras de conversaciones orales coloquiales espontáneas y mayoritariamente secretas que recogen la variedad del español hablado en la ciudad de Valencia. Para incluir otras variedades diatópicas, se ha considerado también el corpus conversacional recogido en el CORLEC.

Tras la búsqueda de los elementos en las transcripciones, se ha procedido a catalogar sus valores según la clasificación detallada en la sección 4 (Garachana 2008 para encima y Pons 2013 para o sea). Esta catalogación ha proporcionado datos cuantitativos sobre la presencia de los valores de cada marcador. En cuanto al estudio fónico, se ha analizado una muestra más reducida, que abarca aproximadamente un 15\% de los ejemplos de cada marcador, en parte por cuestiones de manejabilidad del corpus y en parte (fundamentalmente) como resultado de haber cribado las muestras no analizables por mala calidad de la grabación, ruido de fondo o presencia del elemento en un solapamiento de turnos. Los ejemplos analizados de Val.Es.Co. 2.0 se obtuvieron a través del subcorpus que se encuentra alineado con la transcripción mediante el programa ELAN, todavía no disponible online. Todos los ejemplos fueron procesados mediante el software PRAAT.

\subsection{Análisis acústico. Problemas y decisiones operativas}

A la hora de establecer la prominencia prosódica del fragmento, como se avanzaba anteriormente, Wichmann señala dos parámetros: los paradigmáticos, según los cuales la tonicidad es una muestra de prominencia fónica y la atonicidad, de lo contrario; y los sintagmáticos, según los cuales la menor prominencia fónica corresponde con la integración en GE adyacentes, esto es, la falta de independencia entonativa. Para cubrir estos dos aspectos, se han analizado los siguientes parámetros.

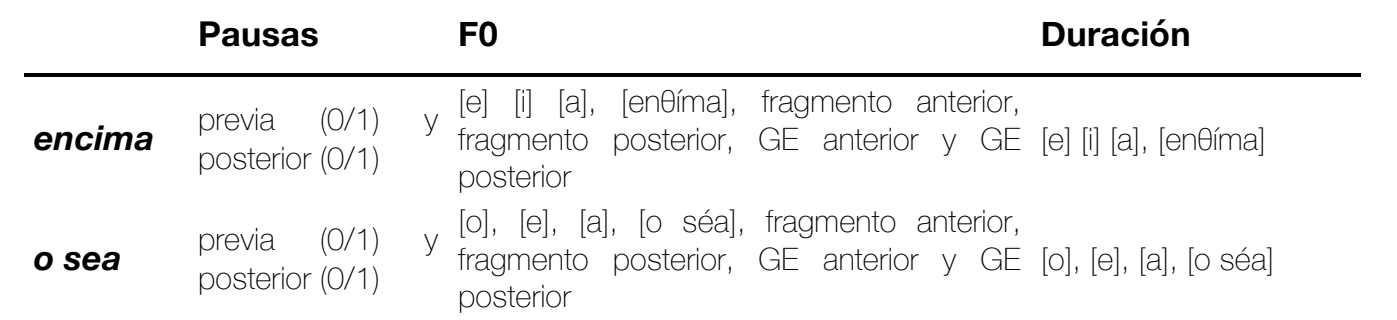

Tabla 1. Parámetros fónicos analizados

En cuanto a los aspectos paradigmáticos, la localización de la sílaba tónica en conversación real es una labor más compleja que en el habla de laboratorio. Los criterios tradicionalmente manejados para identificar la tónica - esto es, la mayor intensidad, altura tonal (F0) y duración - se alteran en el flujo real de la conversación al verse las palabras incluidas en segmentos más amplios, con contornos entonativos que pueden resultar en que, por ejemplo, la F0 más alta de un grupo entonativo corresponda con una sílaba que, pronunciada la palabra fuera de contexto, sería átona. Dejando a un lado los debates sobre cuál de los tres criterios (duración, F0 o intensidad) es el que mejor identifica la tónica, en este trabajo se ha seguido el criterio de Fernández Planas y otros (2002), según la cual, para que una tónica se perciba como tal, su FO ha de ser, como mínimo, 1,5 st más alto que la de las átonas de su grupo acentual. por lo que respecta a los sintagmáticos, se ha 
medido la F0 media de los contornos del MD (tanto los fragmentos anterior y posterior dentro del mismo GE como la F0 media del Ge anterior y posterior al suyo), así como la F0 media del MD. De ese modo, se puede averiguar si este se considera átono o tónico con respecto a los contornos; del mismo modo, se ha analizado la presencia o ausencia de pausa antes y después del MD, para establecer su independencia total (1/1), parcial (1/0 o $0 / 1)$ o inexistente $(0 / 0)$ con respecto a los contornos.

\title{
4 RESULTADOS
}

\subsection{Encima}

El MD encima se incluye en la GDLE (Martín Zorraquino y Portolés 1999: 4095) dentro de los conectores aditivos. Como marcador, se le reconoce un valor que:

\begin{abstract}
vincula dos miembros discursivos con la misma orientación argumentativa, pero encima presenta el miembro del discurso que lo precede como un argumento suficiente para llegar a una conclusión determinada (Martín Zorraquino y Portolés 1999: 4095)
\end{abstract}

A este valor se añade otro en que

\begin{abstract}
el miembro que introduce puede constituir una conclusión opuesta a la esperada del primer miembro. Así, una madre puede regañar a su hija con: Se te compra una cosa y, encima, lloras. De "comprarte algo" lo esperable sería que "estuvieras contenta", pero la conclusión es la contraria: «lloras» (Martín Zorraquino y Portolés 1999: 4095).
\end{abstract}

Finalmente, se le reconoce la capacidad de ocupar él solo un turno de palabra. Estos tres valores discursivos, así como los intraoracionales de los que procede, quedan registrados y ordenados en Garachana (2008) como muestra la Figura 1:

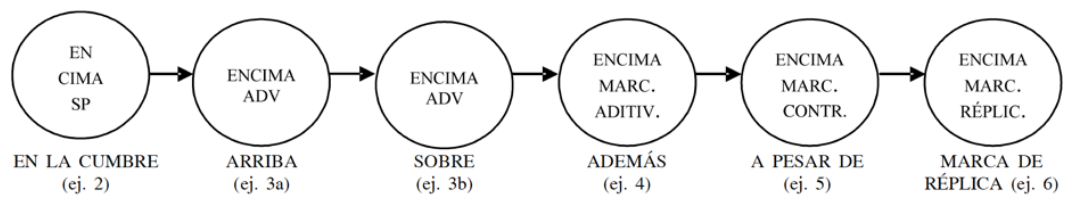

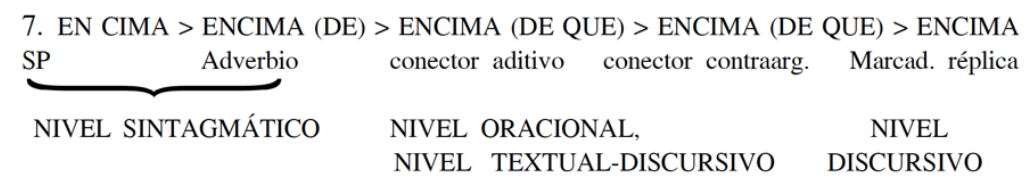

Figura 1. Extraída de Garachana (2008: 13)

Como queda explícito en la Figura 1 de Garachana (2008), se produce un progresivo aumento de ámbito que lleva del nivel sintagmático al discursivo, y de significados locativos a argumentativos. De esta lista, ordenada de más antiguo al más moderno, al menos los cuatro últimos significados han pervivido en español actual y son rastreables en corpus. El primero, adverbial; los demás, reconocidos en la GDLE, con valor aditivo, 


\section{normas}

¿Se puede determinar el grado de gramaticalización de los marcadores del discurso a través de la prosodia? | Maria Estellés

contraargumentativo y de réplica ${ }^{2}$. Así pues, se establecen cuatro valores, que servirán para catalogar los ejemplos del corpus

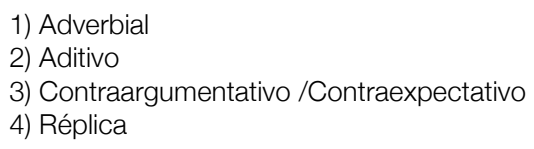

Una vez catalogados los 152 ejemplos arrojados por los corpus, la distribución queda como muestra la Tabla 2:

\begin{tabular}{llllll} 
& adverbial & aditivo & $\begin{array}{l}\text { contraargumentativo/ } \\
\text { contraexpectativo }\end{array}$ & Réplica & Total \\
\hline Val.ES.CO. 2.0 & 22 & 38 & 12 & 4 & $79^{\mathbf{3}}$ \\
CORLEC conversacional & 33 & 14 & 9 & 2 & 58 \\
Resto CORLEC & 15 & 0 & 0 & 0 & 15 \\
Total & 70 & 52 & 21 & 6 & 152
\end{tabular}

Tabla 2. Recuento de los valores de encima en los corpus

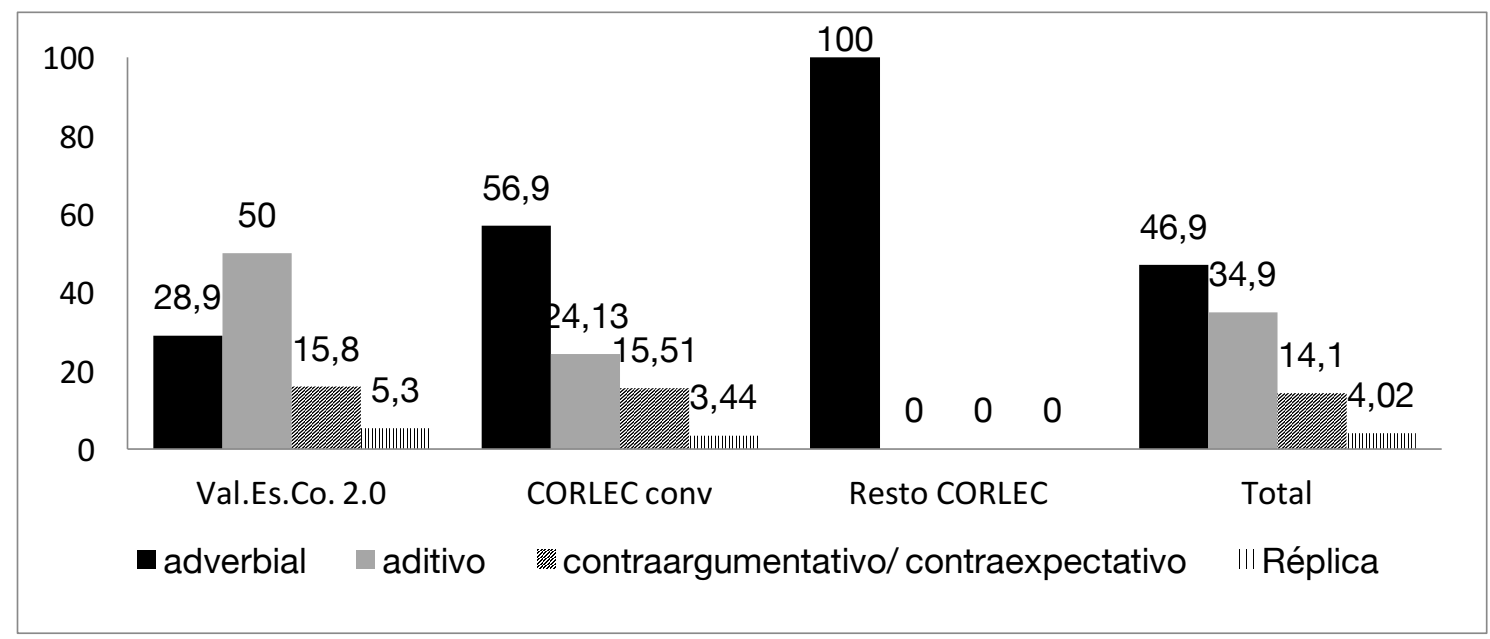

Gráfico 1. Porcentaje de los valores de encima en los corpus

Como muestra el gráfico 1, pese a que, en el cómputo global de nuestro corpus, el adverbial es el valor más frecuente, con cerca de un $50 \%$ de los ejemplos, el porcentaje de valores discursivos es muy superior al registrado por Garachana (2008) sobre la base del CREA, que es eminentemente escrito. Además, opera una especialización muy llamativa en cuanto a variedades diafásicas: en el corpus Val.Es.Co. 2.0, que recoge exclusivamente registro coloquial o informal, la suma de los valores discursivos triplica a los adverbiales, y solo el valor aditivo ya supone un $50 \%$ de los casos. En cambio, en el CORLEC no

\footnotetext{
2 Este último se desprende de su posición independiente, esto es, como único miembro de una intervención (cf. Briz et álii 2002) y, por tanto, presente en el diálogo.

${ }^{3}$ Existen tres casos dudosos, en los que se reconocen funciones no adverbiales, pero cuya adscripción exacta no queda clara por el contexto. En ocasiones, se inscriben en conversaciones laterales o están desencadenadas por un contexto que desconocemos con los datos que nos proporcionan las transcripciones.
} 


\section{normas}

¿Se puede determinar el grado de gramaticalización de los marcadores del discurso a través de la prosodia? | Maria Estellés

conversacional, que incluía textos políticos, administrativos, científicos y humanísticos, la tendencia es inversa: no se recoge ningún caso discursivo. En este sentido, la distribución de encima es distinta a la de o sea, que, como se mostrará en la \$4.2, tiene menores restricciones de registro.

Como se avanzaba en la §3, el análisis fónico de los ejemplos del corpus se ha realizado con una selección de los ejemplos anteriores. En Garachana (2008) se realiza un estudio fónico basado en ejemplos de habla no espontánea. A medida que se vaya caracterizando fónicamente cada valor, se pondrá en comparación con los resultados obtenidos por el trabajo de Garachana.

a) Valor adverbial

Bajo este epígrafe se han englobado, en realidad, dos casos distintos: aquellos en los que encima actúa como un verdadero adverbio (1) y aquellos en que lo hace como locución prepositiva (2)

\footnotetext{
(1) Y la explicación es muy sencilla. Esto ya es... esto ya es geometría pura: Si tú coges una chapa y la doblas, piénsalo, tiene un ángulo de tiro. Entonces le pones otra encima, la encolas, ya tiene otro ángulo de tiro. Pones otra encima, la encolas y ya tiene otro ángulo de tiro (ccon0022d)

(2) o s- estuvim- estábamos los dos hechos polvo/ durmiendo encima de dos mesas $\rightarrow$ / porque dormimos (risas) $\rightarrow$ / y yo le dije $\uparrow /$ va $\uparrow /$ venga $\downarrow$ pues ya de paso me invitas a desayunar (Val.Es.Co. 2.0 Conv 023, int. 077)
}

Como adverbio, la principal característica que encontramos es la esperable según la mayoría de los estudios de gramaticalización: no se registran ejemplos de atrición fónica y se trata de una palabra tónica. En ejemplos de registro menos informal (1), la [i] es claramente la sílaba tónica, ya que en ella confluyen el pico tonal y el de intensidad (no así la mayor duración, que tanto en este como en casi todos los ejemplos de todos los valores tiende a aparecer en la [a]):



Figura 2. Estilización de la curva melódica de [encima] en (1)

Sin embargo, y en línea con las dificultades señaladas para establecer la sílaba tónica (Llisterri y otros 2006), en [enӨíma], en el habla informal la í no es ni la vocal más intensa ni la más larga, y ni siquiera tiene la F0 más alta. Estas características (especialmente las dos últimas) aparecen mayoritariamente en la [a], aunque comparten la relativa prominencia y la no atrición.

En su uso como locución prepositiva se registran valores muy poco prominentes. Ni la sílaba tónica se percibe claramente en la secuencia [enӨíma], que muestra una F0 global similar a la de las sílabas átonas de los contornos. Además, aparece integrada en posición 


\section{normas}

¿Se puede determinar el grado de gramaticalización de los marcadores del discurso a través de la prosodia? | Maria Estellés

media del GE que la aloja. Compárese, en este sentido, la estilización de la curva melódica de (2) en la Figura 3, ejemplo tipo de uso como locución prepositiva, con la del ejemplo (1) en la Figura 2, de uso adverbial:



Figura 3. Estilización de la curva melódica de [encima] en (2)

La construcción de la que proceden ambos usos, el adverbial y el prepositivo, se ha perdido en español; ambos valores se suponen más erosionados prosódicamente que el original y, en especial, el uso como locución prepositiva.

Cabe señalar que los valores discursivo-textuales no derivan del valor de encima como locución prepositiva, sino del adverbial. Este, el menos reducido en el nivel del grupo acentual, muestra, sin embargo, poca prominencia en comparación con sus contornos. Encima adverbial presenta una altura tonal menor que sus contornos en un $80 \%$ de los ejemplos de nuestro corpus.

b) Aditivo

A continuación, sin embargo, se observará el primero de los valores como elemento discursivo, el aditivo. Un ejemplo de este valor es (3), cuyo espectrograma y cuya estilización de encima puede verse, respectivamente, en la figura (4) y la figura (5):

(3) dice ¿os da igual pechuga? / y decimos bueno vale pues si es pechuga pues pechuga vale / digo pero rápido que tenemos-/ hemos quedado con los corredores en un kilómetro/ y llevamos más de media hora aquí/ y aún no nos habéis servido los bocadillos // digo es que esto ya no puede ser y tal sí sí sí sí/ vale vale/ pues bien/ perfecto/ y nos trae eso/ los dos bocadillos envueltos/ que yo para mí /que nos los ha coloca(d)o/ de otros que los habían pedido/ pa(ra) llevar/ nos lo colocan allí/ encima una era de tortilla con queso/ y la otra/ de lomo con tomate

Val.Es.Co. 20. Conv. 48 (en prensa)

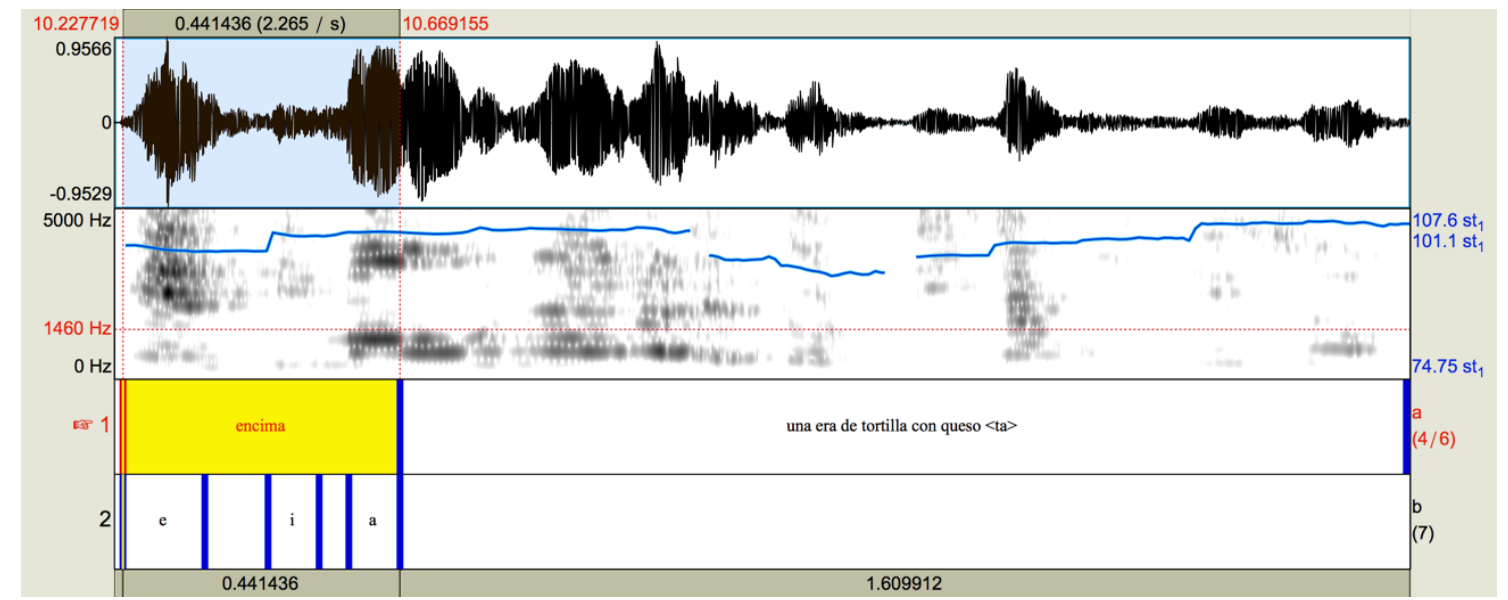


Figura 4. Espectrograma de (3)



Figura 5. Estilización de la curva melódica de encima en (3)

Si se compara este ejemplo de encima aditivo con el adverbial anterior, se observa una menor modulación en el aditivo; no obstante, hay otros cambios asociados, como se muestra en la Tabla 2:

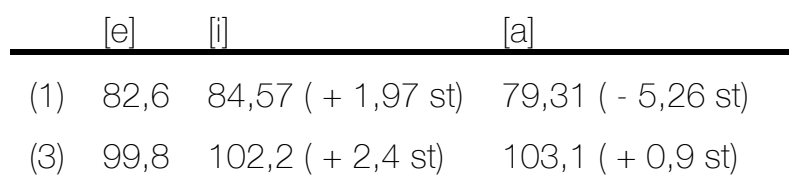

Tabla 3. F0 de [e], [i] y [a] en (1) y (3)

Para empezar, la subida desde la pretónica a la tónica se da en ambos casos (incluso más acentuada en (3), pero en (1) hay una caída drástica que convierte la [a] en átona; esto no sucede en (3) que, en línea con lo sucedido en ejemplos adverbiales en habla informal, mantiene el tono de la [i] en la [a]. En muchos ejemplos aditivos (75\%), de hecho, incluso aumenta significativamente la altura tonal de la [a], de modo que el fragmento se percibe bien con un tono ascendente, bien con un tono similar en la [i] y en la [a] (con una diferencia no superior a 1,5 st). La curva entonativa, por tanto, se aplana con respecto al valor más antiguo.

En cuanto a su comportamiento como fragmento, la mayoría de los casos no presentan reducción fónica y se perciben más prominentes que su contorno (en un $50 \%$ de los casos) o sin diferencia con este (en un 38\%). Solo un 10\% de los ejemplos se percibe como menos prominente que su contorno. Esta situación contrasta con lo registrado en los casos adverbiales, que por lo general (80\%) se percibían en nuestro corpus como más bajos que su contorno. En cuanto a su estatus de GE independiente, todos los ejemplos están integrados en otros GE; la mayoría ocupa la posición media de un GE, y cerca de un 30\% se encuentran integrados con el GE siguiente, en posición inicial.

La consecuencia derivada es que, en términos paradigmáticos, la estructura parece aplanarse tonalmente. Sin embargo, en cuanto a los paradigmáticos, se percibe en su conjunto como más prominente que su entorno.

c) Contraargumentativo 


\section{normas}

¿Se puede determinar el grado de gramaticalización de los marcadores del discurso a través de la prosodia? | Maria Estellés

Los casos de encima que presentan este valor son parafraseables por 'y sin embargo', (4):

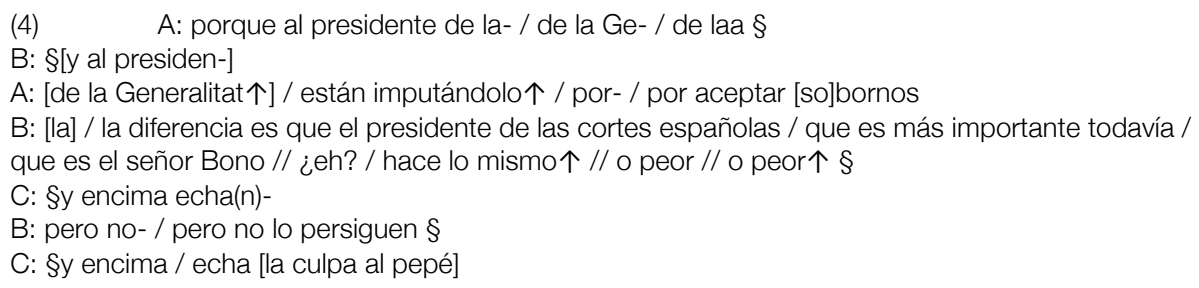

En (4), la hablante C completa el enunciado de B:

el presidente de las cortes españolas (...) hace lo mismo o peor (...) y encima (= a pesar de ello) echa la culpa al PP

Prosódicamente, no parecen presentar grandes diferencias en su comportamiento, salvo una cierta tendencia a elevar, todavía algo más, la F0 de la [a], todavía no suficiente como para quedar plasmada en la estilización de la curva melódica, Sí que se repite un pico de intensidad en la [a]. Esta elevación se ve en el ejemplo (5); la curva melódica estilizada de encima se muestra en la Figura 6:

(5) D: (...) yo no me lo creía cuando me lo dijisteis que que le habían denunciado por darle una patada a un perro que[ estaba en (...)

B: era un era un perro que había salido de una operación quirúrgica de orejas / era un cachorro / tenía // TENÍA[ seis meses / entonces / se va por las ca- se va por la iglesia /(...) por esos alrededores (( )) // y el perro个 se [le ocurre mear (...) en la escalinata de la iglesia / (...) y el-en ese momento (RISAS) el Puerco salía / se abrió la puerta y cogióo yy le metió una patada aal perro //

D: jmadre míaa!

B: lo dejó para el arrastre /

D: (RISAS)

B: y cogió la mujer le pega una patada / y y cogió él se echó para se echó para atrás / y le dio una torta a la mujer que la dejo ahí tirada $\uparrow$

D: (RISAS) //

B: y y cogen y es que encima / encima que lo denuncian / suelta que para el caso // se ve que la la dueña esa del perro个 //

D: sí

B: ha-habíaa // se iba aa casar (...) [ y queríaan querían unos fotógrafos / contratados por su cuenta y (...) y el el (( )) que decía que no que los tenía que contratar él /(...) quee no le parecía bien

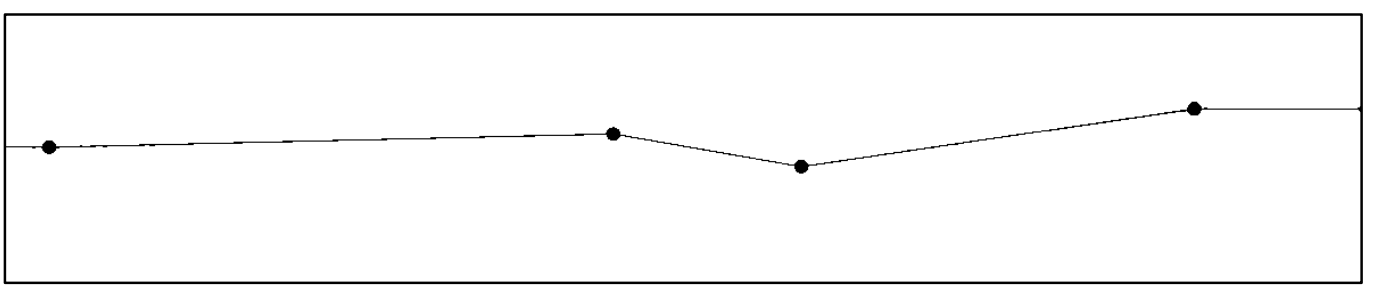

Figura 6. Estilización de la curva melódica de encima en (4)

De nuevo, concebido globalmente, el fragmento encima tiende, o bien a contrastar con su contorno y percibirse como prominente con respecto a él, o bien a mantenerse en una altura tonal similar. En todo caso, son muy escasos los ejemplos de bajada global de la F0 con respecto al discurso anterior o posterior. Sin embargo, la duración media del fragmento [encima] es más breve ( 0,3 s. frente a 0,45 de los aditivos). 
d) Marcas de refutación

El último paso de la evolución, según Garachana (2008), consiste en el desarrollo de una marca de refutación a partir del valor contraargumentativo:

\begin{abstract}
encima replicativo acostumbra a ser una respuesta a una intervención previa en la que se da alguna instrucción o se hace alguna aserción que el hablante considera injusta, excesiva o abusiva. En estos usos, encima no enlaza partes de un mismo enunciado, sino que él solo expresa la disconformidad del hablante ante la información formulada por el interlocutor en el turno de habla inmediatamente anterior, disconformidad que se infería del contexto discursivo en el empleo del encima contraargumentativo (Garachana 2008: 26)
\end{abstract}

Un ejemplo de este valor es (6):

(6): MJ: o sea que volvieron [vamos]

M: [ee siil/ los últimos volvieron a lass/ no sé si fue a las siete o a las diez de la mañana/ creo que fue a las diez de la mañana/// y nadaa/ cuando me levanté $\uparrow$ / a la una/ fui la última en levantarme/ ¡qué vergüenza!

MJ: jencima!

M: encima

MJ: bueno tú te acuestas la primera y te levantas la última/ ¡bien!

Se trata de un ejemplo cuya configuración entonativa se aleja de sus precedentes y se acerca a la del valor adverbial primigenio. La [i] tiende a mostrar la mayor altura tonal e intensidad (de nuevo, no la mayor duración) y la estilización de la curva melódica vuelve a mostrar una caída en la [a]:

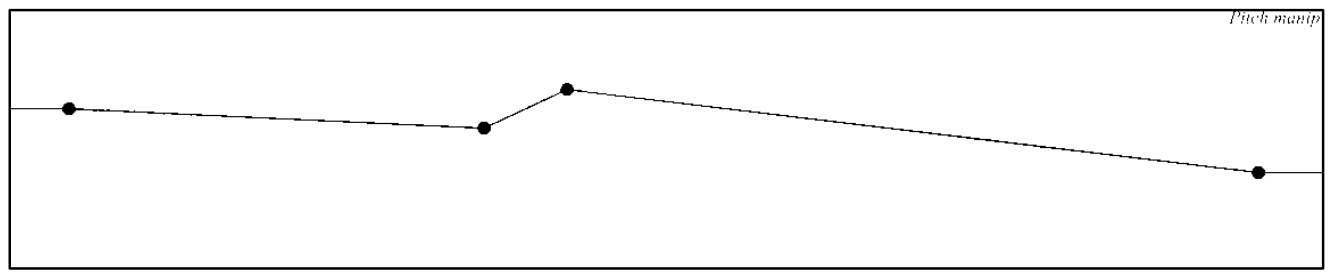

Figura 7. Estilización de la curva melódica de encima en (6)

\title{
4.1.1 Los valores de encima y sus correlatos prosódicos
}

La tabla 4 muestra la comparación entre las curvas melódicas de los distintos valores de encima. 


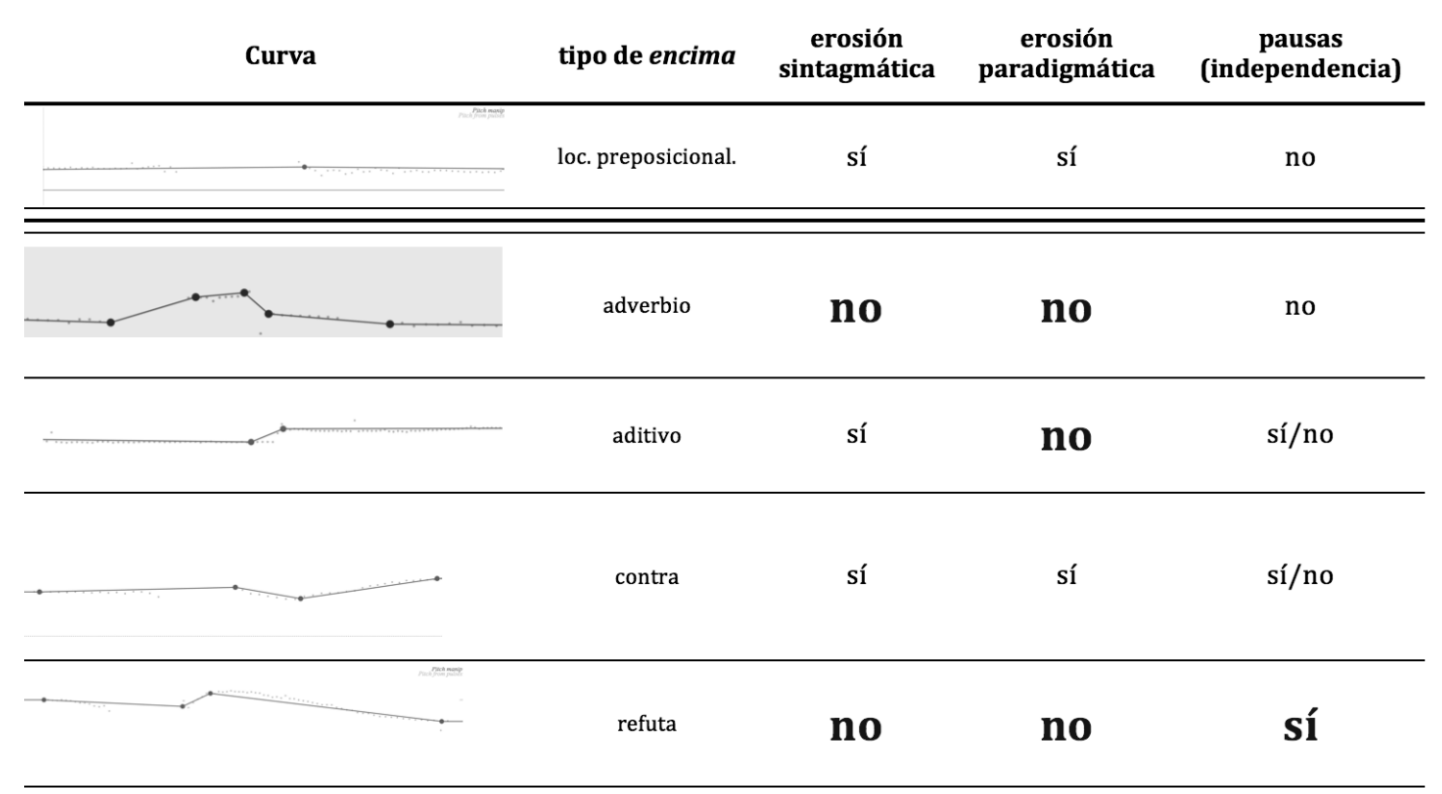

Tabla 4. Comparación de curvas entonativas en todos los valores de encima

Como puede observarse, desde el punto de vista paradigmático, la parte postónica del elemento parece ser la más determinante a la hora de establecer sus valores y la que más cambia de unos a otros: mientras que hay un descenso en el adverbio y el refutativo, hay mantenimiento o, a lo sumo, una subida de FO poco marcada en el aditivo y el contraargumentativo. Las más moduladas - que, además, mantienen la [i] como sílaba con la mayor altura tonal y, en la mayoría de los ejemplos, también con el pico de intensidad - son los valores adverbial y refutativo.

Interpretando los ejemplos a la luz de la teoría de Wichmann, a primera vista, los valores más planos y, por tanto, con menos tonicidad 'interna' serían (además de la loc. prepositiva, fuera de nuestro camino de gramaticalización), el aditivo y el contraargumentativo. En este sentido, los dos primeros valores discursivos surgidos a partir del adverbial sí muestran una erosión prosódica paradigmática y, además, el más moderno muestra más erosión sintagmática también, de acuerdo con lo esperable. En cambio, la parte que no responde a las expectativas es la última: en términos de prominencia prosódica, el último de los valores surgidos, el refutativo, es el más prominente, incluso más que el valor adverbial más antiguo. De hecho, una de las características de este último valor es la tendencia a aparecer completamente aislado, como único miembro de una intervención (lo que, por otro lado, impediría en principio que fuera átono o no contrastara con su contorno). Por tanto, su grado de integración, al menos en esos ejemplos como palabra única, es inexistente: es máximamente prominente.

\subsection{O sea}

El marcador o sea se incluye en la GDLE como reformulador explicativo. Los reformuladores se presentan como elementos que se emplean (Martín Zorraquino y Portolés 1999: 4121): 


\title{
normas
}

¿Se puede determinar el grado de gramaticalización de los marcadores del discurso a través de la prosodia? | Maria Estellés

\begin{abstract}
para presentar el miembro del discurso que lo sigue como una mejor expresión de lo que pretendió decir con el miembro precedente(...) La reformulación va desde la explicitación de un primer miembro que pudiera ser mal comprendido, (...), hasta la rectificación (...) Ahora bien, en todos los casos, se mantiene que, en lugar de lo anteriormente dicho, la nueva formulación es el miembro que se ha de tener presente en la prosecución del discurso.
\end{abstract}

La GDLE también da claves que explican su evolución diacrónica: a diferencia de los conectores, que unen dos miembros discursivos, en los reformuladores el énfasis se pone en el segundo miembro, el que introducen. Tal es la importancia de este segundo miembro que, en muchas ocasiones, es posible omitir el primero (implícito), puesto que solo es el segundo el que se ha de tener presente. Esta circunstancia "explica la facilidad con que los reformuladores evolucionan hasta convertirse en operadores" (Martín Zorraquino y Portolés 1999: 4121).

Esta evolución queda reflejada en la historia de o sea, trazada en Pons (2013) -y, centrada en el siglo XX, en Pons (2014) - para los cuales sugiere el orden

paraphrastic reformulative $>$ conclusive $>$ non-paraphrastic $>$ modal.

TABLE 7.7 Syntactic liberation and semantic specialization in the $o$ sea construction

\begin{tabular}{|c|c|c|c|c|c|c|}
\hline $1200-1300$ & $1500-1700$ & 1620 & 1831 & 1921 & 1938 & 1978 \\
\hline $\begin{array}{l}\text { O sea po } \\
\text { sea q o r } \\
\text { Sea p o sea } \\
\text { q or }\end{array}$ & $\begin{array}{l}\mathrm{p} \text { o sea } \mathrm{q} \\
\text { (reformul } \\
\text { ative) }\end{array}$ & $\begin{array}{l}\text { p O o sea } \\
\text { que } \mathrm{q} \\
\text { (conclusive) }\end{array}$ & & & & \\
\hline \multirow[t]{4}{*}{$\begin{array}{l}\text { Sea p o sea } q \\
\text { p o sea que q }\end{array}$} & & & $\begin{array}{l}\text { p o sea que... } \\
\text { (conclusive) }\end{array}$ & & & \\
\hline & & & & $\begin{array}{l}\text { A: } p \\
\text { B: o sea } q \\
\text { (heteroreformulative) }\end{array}$ & & \\
\hline & & & & & $\begin{array}{l}\text { p. O sea: } \\
\text { q (concl) }\end{array}$ & \\
\hline & & & & & & $\begin{array}{l}\text { p. o sea. } \\
\text { (modal) }\end{array}$ \\
\hline
\end{tabular}

Tabla 5. Extraída de Pons (2013: 134)

Esta línea del tiempo se resume en tres cadenas: 
First, there seems to be a diachronic path from self-reformulation (either paraphrastic or nonparaphrastic) to hetero-reformulation, and from equivalency to correction. (...) From that initial point, RMs can evolve into other discourse relations that may come to include correction, though this is not always the case. Once the range of paraphrastic values in the scale equation-correction is fulfilled, a paraphrastic marker is able to convey heteroreformulation relationships, so the following cline is proposed:

self-reformulation>hetero-reformulation (Pons 2013:134; nuestra cursiva).

TABLE 7.14 The end of the road (II): development of formulative values

\begin{tabular}{|c|c|c|c|c|c|}
\hline Unit & \multicolumn{2}{|l|}{ Sub-act } & \multirow[t]{2}{*}{ Act } & \multicolumn{2}{|c|}{ Intervention } \\
\hline Posit & DSS & SSS & & Initiative & Reactive \\
\hline Initial & $\begin{array}{c}\text { Conclusion } \\
\text { po sea que } q \\
1613 \\
\text { po sea... } \\
1831 \\
\text { Non- } \\
\text { paraphrastic } \\
\text { reformulation } \\
\text { po sea } q \\
1705-43\end{array}$ & $\begin{array}{c}\text { Paraphrastic } \\
\text { reformulation- } \\
\text { p o sea } q \\
1379-1753\end{array}$ & $\begin{array}{l}\text { Paraphrastic } \\
\text { reformulation } \\
\quad \text { P. O sea q } \\
\longrightarrow \\
\longrightarrow\end{array}$ & & $\begin{array}{c}\text { Hetero- } \\
\text { reformulation } \\
\text { A: } p \\
\text { B: } o \text { sea } q \\
1926 \\
\\
\text { A: } p \\
\text { B: } o \text { sea.... } \\
1957\end{array}$ \\
\hline Medial & & & $\begin{array}{c}\text { Formulation } \\
\text { po sea p' } \\
(1940-1970 ?)\end{array}$ & & \\
\hline Final & & & $\begin{array}{l}\text { Stressing } \\
\text { p. O sea. } \\
(1978)\end{array}$ & & \\
\hline
\end{tabular}

Tabla 6. Extraída de Pons (2013: 134)

a) Reformulador parafrástico

Por tanto, el primero de los estadios identificado por Pons (2013) es el de un reformulador parafrástico, el valor básico que le reconoce la GDLE, mediante el cual se explicita de un modo percibido como más adecuado lo dicho anteriormente.

El análisis prosódico revela un alto grado de heterogeneidad en estos ejemplos. En cuanto a la presencia de erosión fónica, es muy general la atrición. La [e] es prácticamente imperceptible (en el mejor de los casos, una glide y en la mayoría, inexistente) y la [o] también se elide a menudo, con lo que se da la pronunciación [sá]. Cabe decir que, en los tres ejemplos que hemos encontrado en los que la secuencia o sea se encuentra entre pausas (es decir, forma GE propio e independiente), la [e] sí aparece, sin reducir, y presenta la mayor altura tonal.

Si se compara la estilización de la curva melódica de varios ejemplos, se puede observar la diversidad: 


\begin{tabular}{|c|c|c|}
\hline (7) & $\cdots$ & $\begin{array}{l}\text { [RISAS] y encima es el típico que se picaa } \\
\text { que flipas/o sea que [se toma] las cosas en } \\
\text { serio a lo mejor una persona que sabe que } \\
\text { juega mal / directamente juega de risa o eso } \\
\text { no se dedica aa // por eso que n- no te } \\
\text { enfaadas / y te pones en plan serio sabiendo } \\
\text { que no das ni una }\end{array}$ \\
\hline (8) & 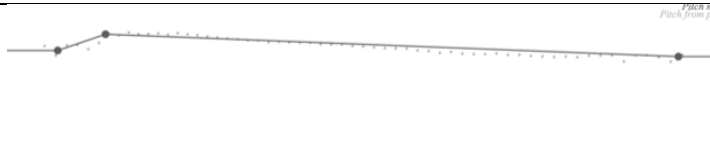 & $\begin{array}{l}\text { een la cultura americanaa / no / escúchame } \\
\text { en la cultura americana y inglesa / se toman } \\
\text { un chupito después /o sea hay que hacer un } \\
\text { brindis de chupitos }\end{array}$ \\
\hline (9) & $\rightarrow$ & $\begin{array}{l}\text { A: [si se comparten gastos se comparten } \\
\text { gastos de (( ))] } \\
\text { B: [si se comparten gastos] se comparten } \\
\text { dineroo / o sea gastos de la casa/ pero es } \\
\text { que luego cada vez que se sale a algún l- } \\
\text { sitioo ipagaría yo! }\end{array}$ \\
\hline (10) & & $\begin{array}{l}\text { A: en negro y au (...) } \\
\text { B: [ya pero] / en negro } \uparrow \text { PiLAR / o sea las } \\
\text { personas que no tienen un contrato/ pero mi } \\
\text { amiga Virginia que está ahíi / [sí que] tiene } \\
\text { contrato }\end{array}$ \\
\hline (11) & $\longrightarrow$ & $\begin{array}{l}\text { mira te regalaban zapatillas (...) más un } \\
\text { conjunto téxtil (sic)/ ee b- o sea de camiseta } \\
\text { y pantalón supongo/ más el dorsal/ del dos } \\
\text { mil quince }\end{array}$ \\
\hline
\end{tabular}

Tabla 7. Comparación de curvas entonativas en todos los valores de o sea

No obstante, hay una puntualización estructural si se toma como referencia el ámbito discursivo del marcador: las curvas más planas $(9,10$ y 11) tienen ámbitos más reducidos (sintagmas/subactos), mientras que las más moduladas tienen ámbito oracional (acto). Esto es, las sintácticamente más integradas son menos prominentes, mientras que las menos integradas (supraoracionales) tienen una prosodia menos erosionada.

En cuanto a la erosión sintagmática, no hay ningún ejemplo más prominente que su contorno. La mayoría de los ejemplos (60\%) tiene, de hecho, un F0 significativamente más baja, y el resto no se muestra significativamente más ni menos prominente. La regularidad sintagmática más llamativa es que en un $85 \%$ de los casos va precedido de pausa. Solo un $15 \%$ no tenían pausa anterior, y se da el caso de que concurren con vacilaciones anteriores (11).

\section{b) Conclusivo}

Las curva entonativa de los ejemplos con valor conclusivo (12), el segundo en la línea del tiempo, son notablemente planas (Imagen XXX):

(12) A: (...) sii / ell hombre este las hubiera violado // ¿tú te crees que esas crías van a ir a buscarlo después?

B: ${ }^{\circ}$ (claro) $)^{\circ}$

A: que o sea quee- que yo no me creo que las haya viola(d)o ni que las haya toca(d)o ni nada/ y digo pero la tía [¿cómo=]
B:
A: =está tan seguraa?§
$[y$ las $\rightarrow]$ 


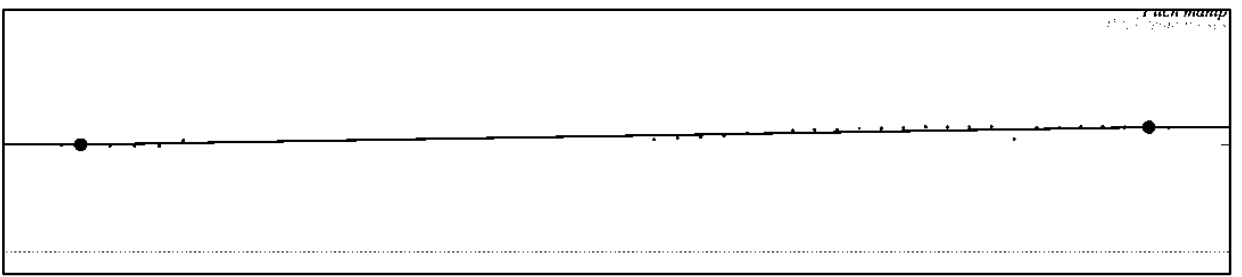

Imagen 8. Estilización de la curva melódica de (12)

La mayoría de los ejemplos con valor conclusivo siguen un patrón similar a este: una curva bastante plana, con poca modulación y, a diferencia de la tendencia observada en el reformulador parafrástico, con un ligero ascenso hacia la sílaba final. En cuanto a su contraste con el contorno, suelen ser menos prominentes o no destacar significativamente. Esta tendencia es similar a la que se observaba en el paso del aditivo al contraargumentativo, en el caso de encima.

c) Reformulador no parafrástico

El valor como reformulador no parafrástico, que surge del parafrástico (no del conclusivo), puede verse ejemplificado en el ejemplo (13), donde la hablante A se corrige: la persona de la que hablan no ha ganado a G., sino que, de hecho, ha perdido contra G:

(13) A: [¿te acuerdas cuando] me contaste que se picó porque había ganado a G.?/ o seaa porque había perdido [contra] G. un montón de veces [y quería] la revancha

La estilización de la curva de o sea en (13), una buena muestra de lo que sucede en los ejemplos no parafrásticos, en los que se corrige lo anterior, es completamente plana y contrasta marcadamente (a la baja) con el contorno.

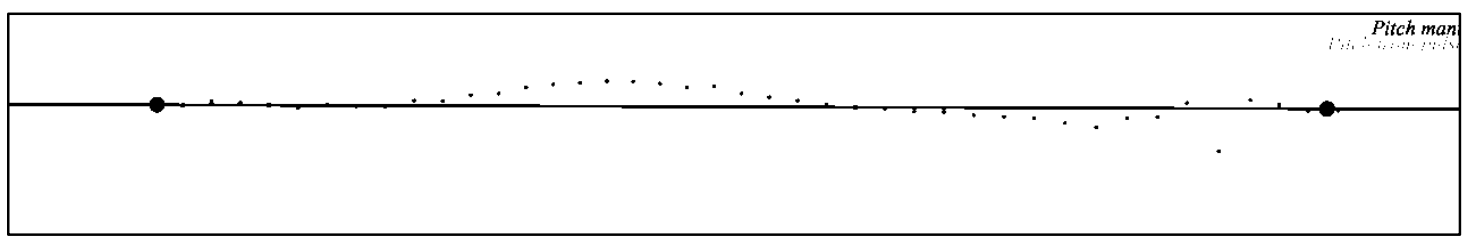

Imagen 9. Estilización de la curva melódica de (13)

Se recoge también una fuerte tendencia al alargamiento de la [a]: se percibe, por tanto, una curva mantenida o, en ocasiones (14), ligeramente descendente:

(14) B: (...) ((se)) hace un precio asii especialillo ((pero)) que en realidad tampoco ees / cobra tanto porque las academias cobra unn ¡PASTÓN! (...) la academia al niño le paga un past- o seaa/ los [padres del niño pagan un pastón] 


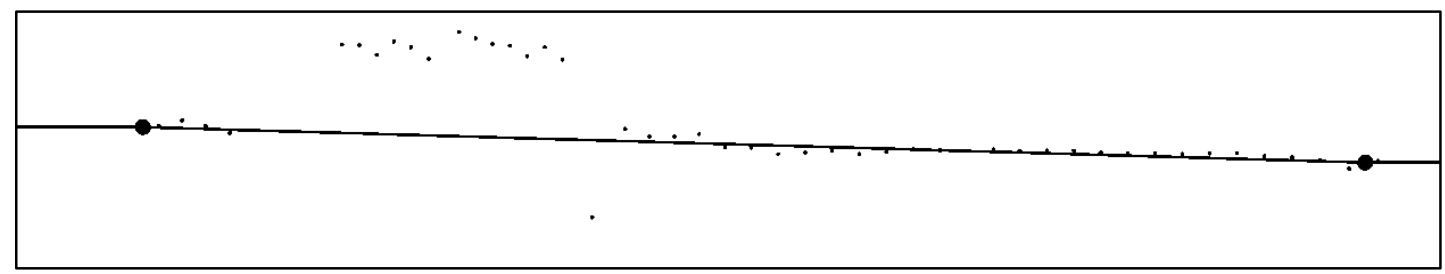

Imagen 10. Estilización de la curva melódica de (14)

d) Aumentos de ámbito

Tras el surgimiento de los valores no parafrásticos, los parafrásticos empiezan a asumir, según Pons (2013), ámbitos más amplios, entre ellos sobre actos. Es el momento de recordar los contrastes que se producían en la curva de la reformulación parafrástica entre los casos de o sea con ámbito sobre subactos y los casos con ámbito sobre actos. Aquí se produce la primera divergencia con la tesis inicial: la tendencia hacia la atonicidad se rompe en este punto, puesto que son más prominentes los ejemplos en los que el marcador afecta a unidades discursivas (o sintácticas, si se quiere) superiores. Llegados a este punto, Pons (2013) señala la aparición de heterorreformulaciones, esto es, operaciones de reformulación referidas a un discurso previo emitido por otro hablante. Es el caso de (15), cuya curva melódica se ofrece en la Figura (11)
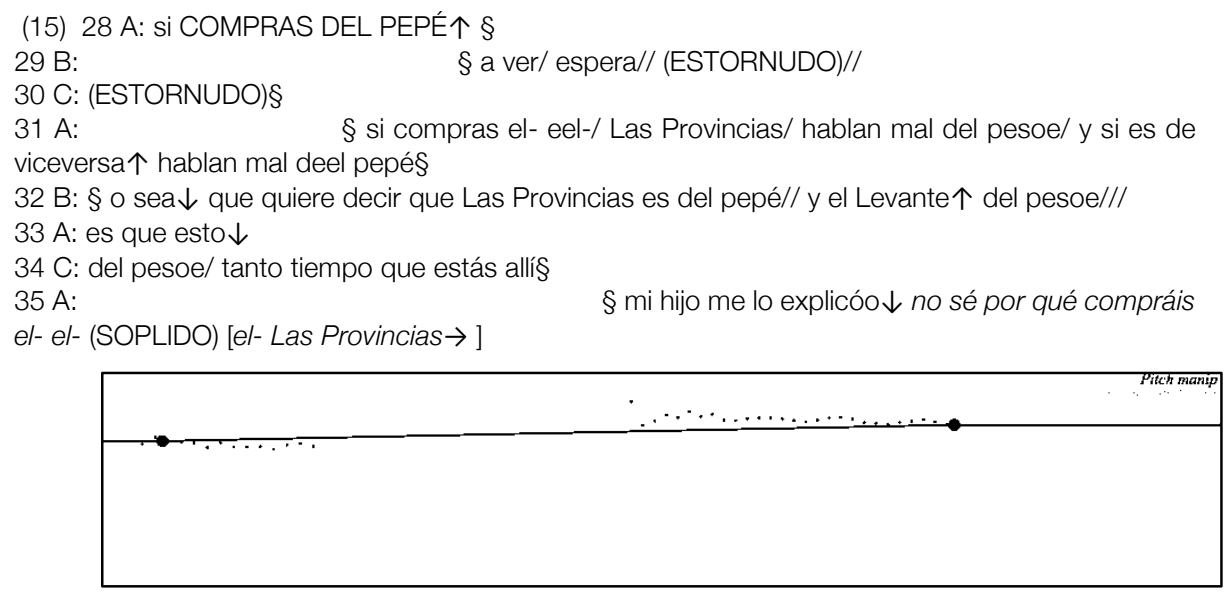

Imagen 11. Estilización de la curva melódica de (15)

Se trata de casos en los que el fragmento se percibe con una curva plana (algo más ascendente que en los anteriores casos), y se percibe más bajo que su contorno, pero está (lógicamente) delimitado siempre por una pausa anterior y en muchas ocasiones, también posterior. Así, su independencia como GE crece.

e) Modalizador

Los valores como modalizador, del mismo modo que los formulativos, no se analizan en el artículo de Pons (2013) desde el punto de vista histórico, dado que su carácter marcadamente conversacional no permite rastrear su historia en textos escritos. Sin embargo, al acudir a corpus se observa cómo la posición inicial y final de acto que ocupan en Pons (2013) no son las únicas en las que pueden aparecer (también pueden tener 
¿Se puede determinar el grado de gramaticalización de los marcadores del discurso a través de la prosodia? | Maria Estellés

ámbito sobre subactos, e incluso palabras). Asimismo, la aparición en posición final del énfasis e inicial de la atenuación no son más que tendencias, a la vista de los datos (véase 16). Atendiendo a su comportamiento prosódico, los enfatizadores se comportan de modo parecido a los reformuladores no parafrásticos: curvas planas, poca tonicidad paradigmática y también sintagmática, como demuestra el espectrograma de (16), donde se aprecia cómo el fragmento sombreado es tonalmente mucho más bajo que los contornos.

(16) iy pegó volantá* en medio del PUENTE! (...) [y] pasa un coche de policía por nuestro la(d)o/ y digo o sea llega a pasar [tres segundos] antes $\uparrow /$ yy/ es que no lo cont-/ o sea inos vamos todos al calabozo! // [io sea pero todos!]

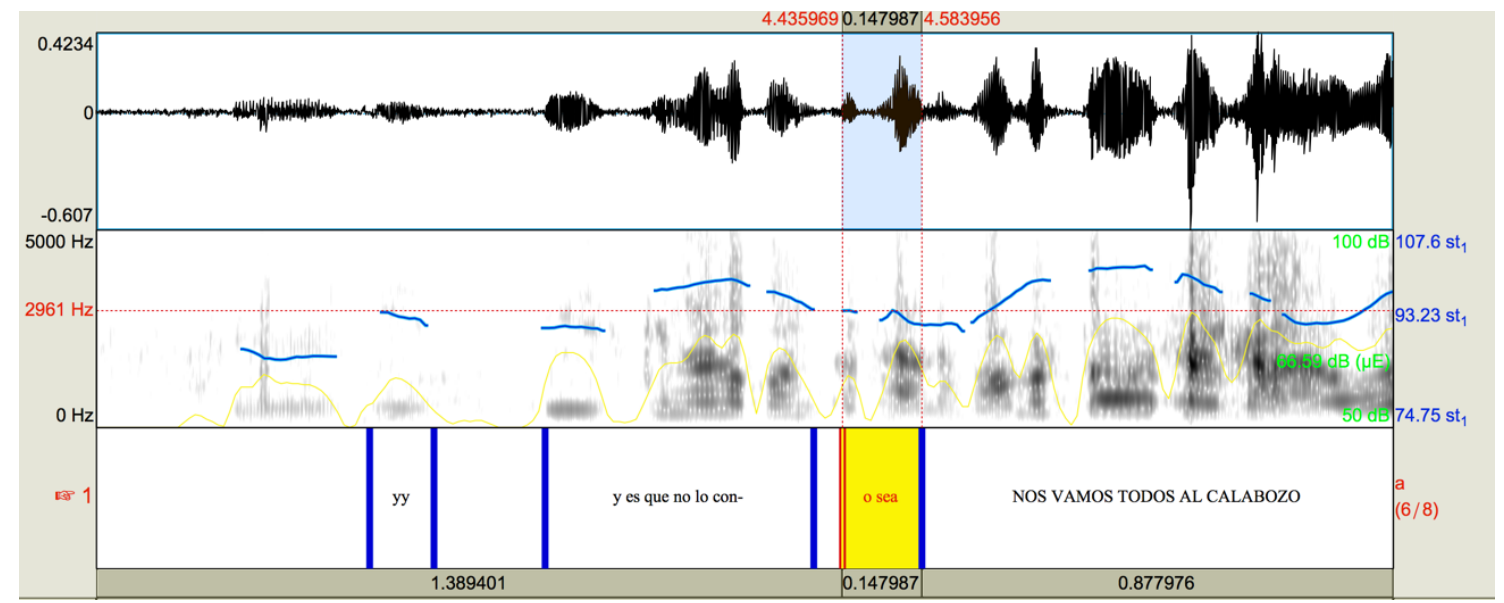

Imagen 12. Espectrograma de (16)

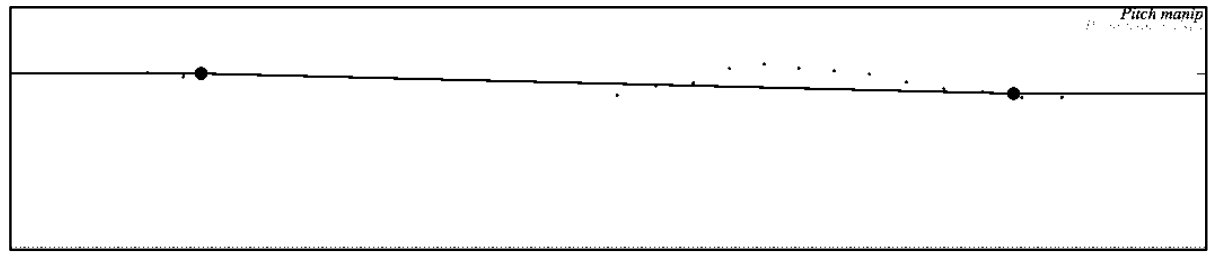

Imagen 13. Estilización de la curva melódica de (16)

Lo mismo sucede cuando o sea se sitúa en posición final (17), cuyo espectrograma (Imagen 13) y curva estilizada de o sea (Imagen 14) se ofrecen abajo:

(17) B: [no no que] te digo que- que de todas formas a ver si entiendes quee hay que tener cuidado con ese tema§

C: $\S$ que es que paso de tocar ese tema [bastante me he comido la cabeza $\downarrow$ ]

B: [no joder] te lo digo Carolina porque un simple me-comentario no se quee Mario sii Mario no sé cuántos Mario§

C: $\quad$ § no no no pienso hablar de él nunca $\downarrow /$ y cuando

lo vea por la calle me voy a desmayar $\downarrow / /$ o sea§

B:

$\S(\mathrm{RISAS}) \S$

C:

lo voy a notar tía

§y además

(Corpus Valesco 2.0, Conversación 20, Intervenciones 239-247) 


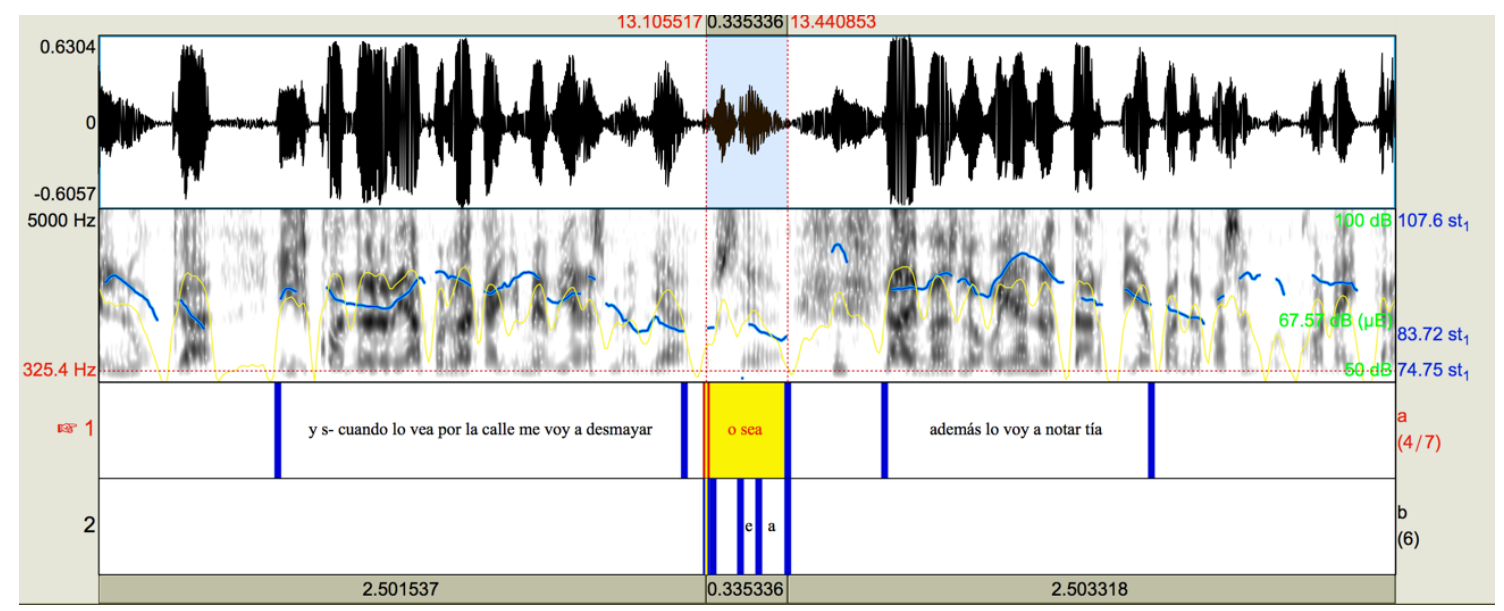

Imagen 13. Espectrograma de (17)



Imagen 14. Estilización de la curva melódica de (17)

No existen grandes diferencias con los atenuadores, salvo en el contraste con el contorno. Esta circunstancia es esperable, dado que el contenido (y no el marcador) es el que recibe el énfasis y, del mismo modo, es el contenido afectado aquel cuya fuerza ilocutiva se pretende aminorar, en el caso de la atenuación (18):

(18): 49 B: [yo cuando acabe quiero estudiar/ algún idioma] yo cuando acabe $\uparrow$ quiero estudiar alemán $\downarrow$ y francés no estudiarlo§

$50 \mathrm{C}$ :

$51 \mathrm{B:}$ [sii]

§ ¿tuú?

52 C: [ruso]

53 B: no estudiarlos a fondo pero por lo menos tener un poco dee- de nivel o sea

$54 \mathrm{~A}:{ }^{\circ}(\mathrm{ya})^{\circ}$

55 B: (()) saber algo vamos

(Corpus Valesco 2.0, Conversación 25, Intervenciones 49-57) 


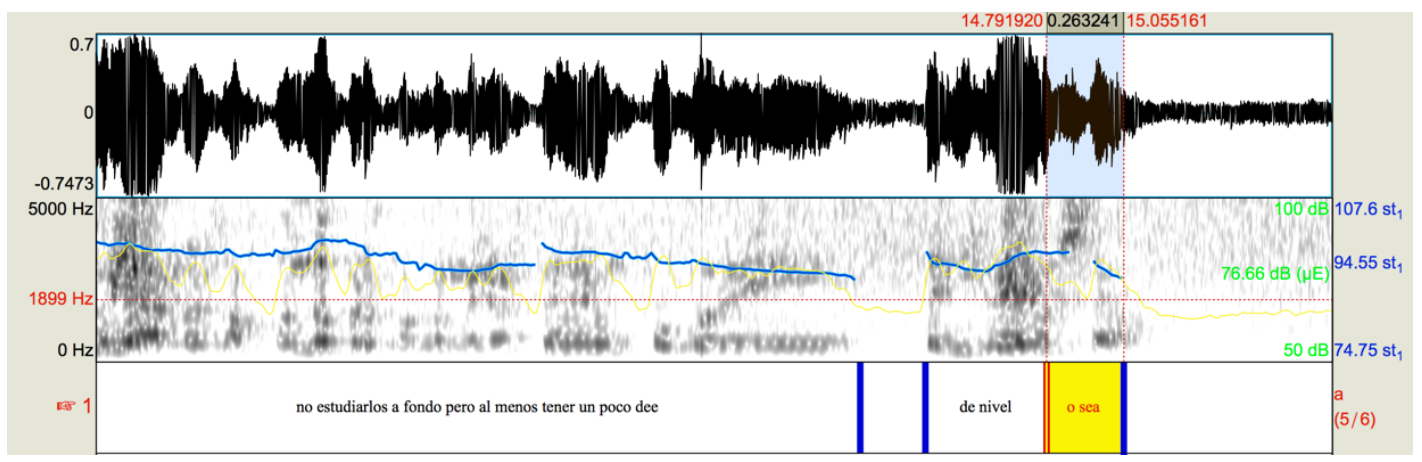

Imagen 15. Espectrograma de (18)

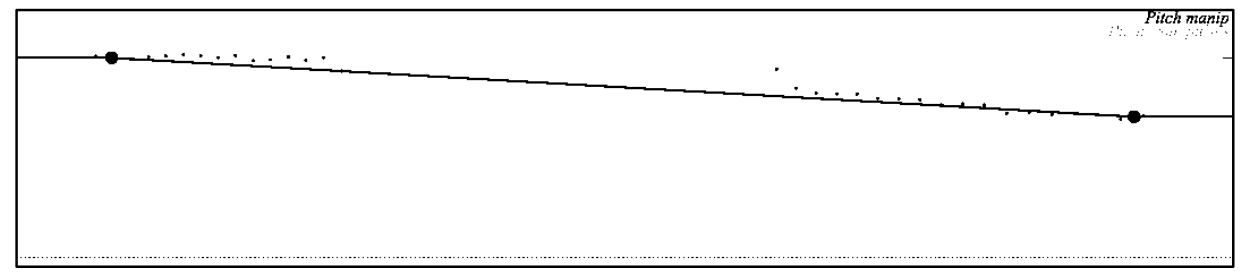

Imagen 16. Estilización de la curva melódica de (18)

En el caso de los valores formulativos (fillers, continuativos), no rastreables textualmente por su carácter marcadamente oral y conversacional, no podemos establecer la fecha de su surgimiento. La hipótesis más razonable sería que, dado su vaciado de contenido (propiamente ya no parafrasean ni corrigen, y tampoco concluyen ni enfatizan), serían, tal vez, los últimos en aparecer. Su principal característica es la presencia de una curva más modulada (cf. Imagen 17, la estilización del ejemplo 19), así como la presencia de un fuerte alargamiento de la [a], en la que recae todo el peso del mantenimiento del turno de habla (se alarga cuanto sea necesario). De nuevo, el contraste con el contorno, si se produce, es a la baja, como puede verse en (19):

(19) [es como] la metodología para dar unn tema een concreto// tú te buscas [una] edad concreta / por ejemplo un curso $\downarrow$ segundo de la eso/ yy te buscas $\uparrow \mathrm{hmm}$ los objetivos que te dan en segundo de la eso como filóloga hispánica $\downarrow /$ pues este año voy a daar / hmm iyo qué sé!/ hmm sigloo/ o sea yo qué sée// hmm generación del veintisiete no sé qué no sé cuántos 


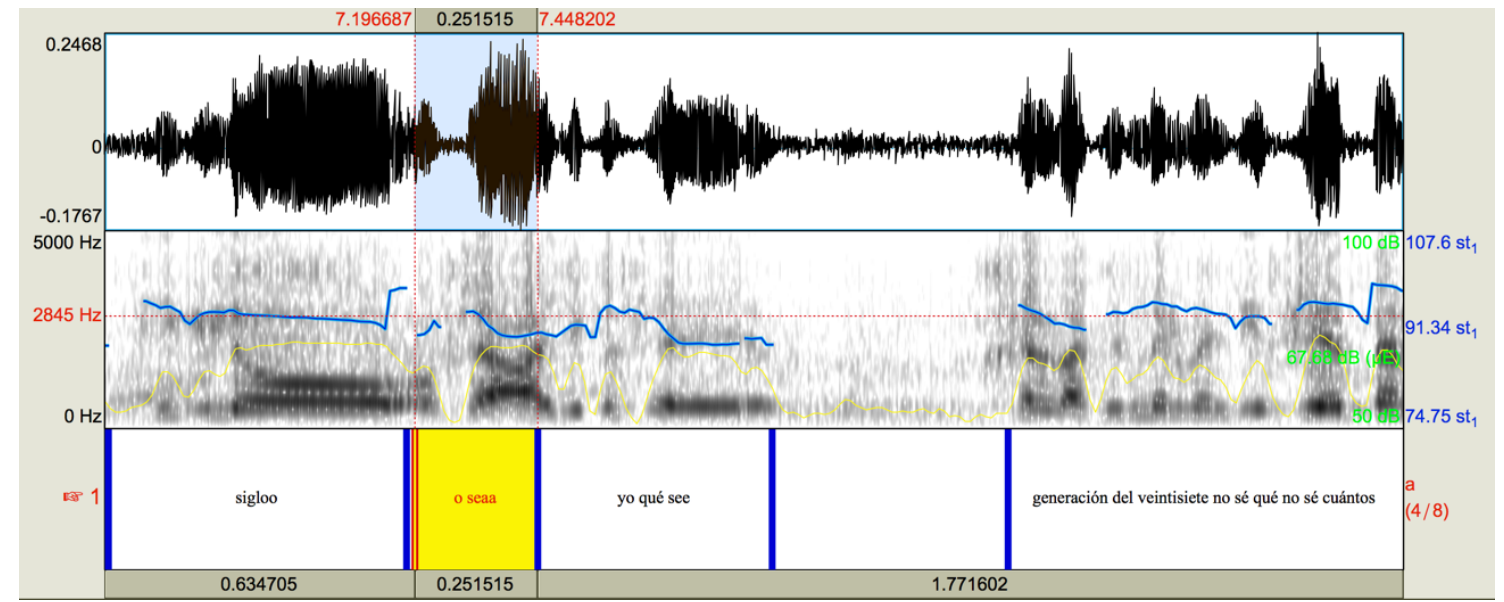

Imagen 17. Espectrograma de (19)

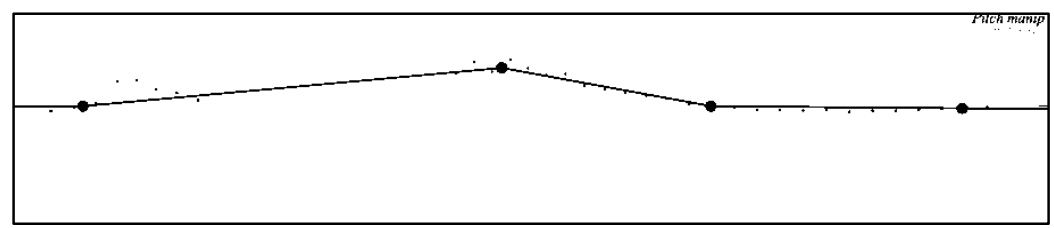

Imagen 18. Estilización de la curva melódica de (19)

\section{CONCLUSIONES}

En líneas generales, hasta un cierto punto de la evolución de ambos marcadores del discurso se puede observar que se cumplen los comportamientos de Wichmann.

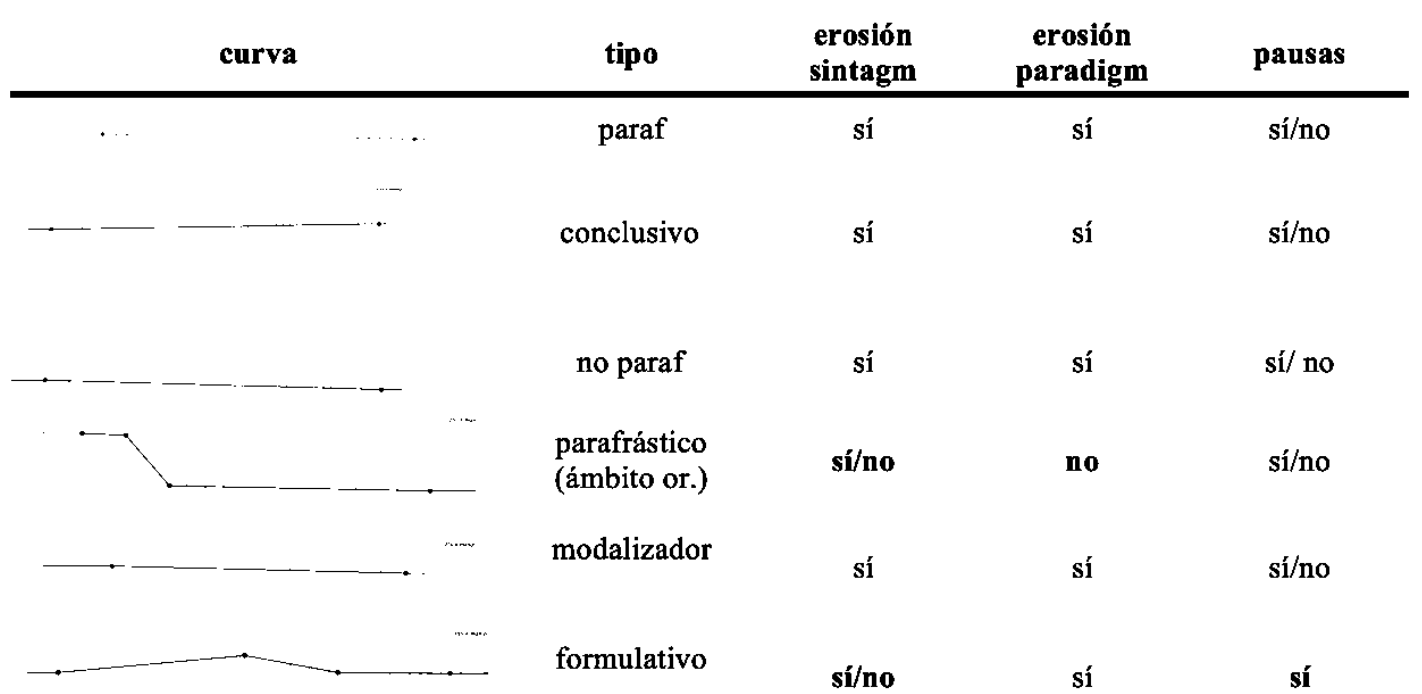

Tabla 8. Evolución de o sea

Sin embargo, tal como sucedía cuando encima se convertía en marcador de refutación, parece haber un cambio significativo en la prosodia cuando se trata de valores que 


\section{normas}

¿Se puede determinar el grado de gramaticalización de los marcadores del discurso a través de la prosodia? | Maria Estellés

incorporan en su significado, en mayor o menor medida, la interacción o, más concretamente, el aquí y el ahora del desarrollo dialógico espontáneo. Sucede, por tanto, en el encima usado como réplica, pero también en los valores formulativos de o sea, asociados al flujo conversacional.

La prosodia parece ser, por tanto, efectiva a la hora de distinguir grandes cambios categoriales (es manifiesta la diferencia entre la locución prepositiva, el adverbio y los marcadores, en el caso de encima), pero menos detallada a la hora de establecer los distintos significados de la forma gramaticalizada, una vez establecido el carácter discursivo, con la excepción aparente (y provisional, a falta de más investigación) de los valores relacionados con la interacción o con el hecho conversacional. Asimismo, en aquellos casos en los que puede haber una ambigüedad relacionada con el ámbito del marcador (en los casos en que éste puede afectar a varias unidades del discurso), también se dan diferencias prosódicas. En los datos de nuestro corpus, al aumento de ámbito (asociado a la gramaticalización) le corresponde, sin embargo, una mayor prominencia prosódica. En el caso de encima, queda pendiente un estudio prosódico de los distintos ámbitos que puede tener cada uno de sus valores.

\section{REtos Futuros}

La cala de corpus que se ha llevado a cabo, en suma, carece de validez estadística: se ha llevado a cabo únicamente con dos marcadores del discurso y en registro fundamentalmente informal. El estudio en este sentido debería ampliarse en varios sentidos:

a) Tonicidad: Además de la dificultad intrínseca de establecer la tonicidad en discurso real (las palabras se someten a configuraciones suprasegmentales, más amplias, que pueden dejar en un segundo plano la manifestación de su sílaba tónica, por ejemplo), existe un problema añadido. Todos los elementos que Wichmann recoge como estudios confirmatorios de la atonicidad de los MD examinan elementos que son, como máximo, bisílabos (of course, sorry, now, enfin). Sin embargo, un simple vistazo a la lista de marcadores del discurso del español (y también de otras lenguas) revela la existencia de un gran número de MD polisilábicos, a menudo por encima de las cuatro sílabas y en ocasiones, con dos sílabas tónicas (dos grupos acentuales) dentro. Es el caso de de todas formas/maneras, en primer lugar o por otra parte. La pregunta es ¿qué ocurre con estos elementos? Si pierden la tonicidad, nos encontraríamos con cinco sílabas átonas seguidas que vendrían a sumarse a otras pretónicas o postónicas de los grupos acentuales siguiente o precedente. Esta circunstancia, si llegara a ser posible en castellano, sería incómoda de pronunciar, dado que el grupo acentual (Garrido 2012) consta típicamente de una pretónica y dos postónicas rodeando a la sílaba tónica.

b) ¿Es válida esta tendencia para todos los MD o existe una especialización dependiendo del tipo de MD? ¿Y dependiendo del registro?

c) Los MD menos frecuentes en el discurso oral ¿también están sometidos a este tipo de reducción prosódica (o fónica)?¿Quedan excluidos los MD gramaticalizados por vía escrita? 
En conclusión, aunque existan ciertos puntos en los que la erosión fónica no parece corresponder con la evolución histórica, los datos preliminares son alentadores y animan a continuar profundizando en la posibilidad teórica de examinar la prosodia de la lengua contemporánea para completar estudios diacrónicos. Asimismo, pueden contribuir en la misma línea otros estudios que también emplean medios de carácter más técnico para detectar en sincronía las consecuencias de la variación diacrónica, como es el caso del rastreo de los movimientos oculares a través de dispositivos de eye tracking, mediante los cuales se constata el distinto procesamiento de los distintos valores y su posible correlación con la etapa de surgimiento histórico (en la línea de Nadal et ál., en prensa o Cuello, en preparación).

\section{BIBLIOGRAFÍA}

Azofra Sierra, M. E. (2012). Procesos de formación de conectores aditivos en español medieval. RILCE: Revista de Filología Hispánica, 28(2), 351-384.

Cabedo, A., \& Pons, S. (2013). Corpus Val.Es.Co 2.0. Retrieved from www.valesco.es

Dehé, N., \& Stathi, K. (2012). Grammaticalisation and prosody: the case of English sort/kind/type of constructions. Reflections on Grammaticalization, 5.

Dér, C. (2013). Grammaticalization: A specific type of semantic, categorical, and prosodic change. Berliner Beiträge Zur Hungarologie. Schriftenreihe Des Fachgebiets Für Ungarische Literatur Und Kultur an Der Humboldt-Universität Zu Berlin, 18, 160-179.

Fernández Planas, A. M., Martínez Celdrán, E., Pàmies, A., Ortega, A., \& Cruz, M. A. (2002). Umbrales tonales en español peninsular. In J. Díaz García (Ed.), Actas del II Congreso de Fonética Experimental (pp. 272278). Sevilla: Universidad de Sevilla.

Garachana Camarero, M. (2008). En los límites de la gramaticalización. La evolución de encima (de que) como marcador del discurso. Revista de Filología Española, 88(1), 7-36.

Garrido, J. M. (2012). Análisis fonético de los patrones melódicos locales en español: patrones acentuales. Revista Española de Lingüística, 42(1), 79-107.

Hirschberg, J., \& Litman, D. (1993). Empirical Studies on the Disambiguation of Cue Phrases. Comput. Linguist., 19(3), 501-530. Retrieved from http://dl.acm.org/citation.cfm?id=972487.972490

Marcos Marín, F. (Ed.). (1992). Corpus Oral de Referencia del Español Contemporáneo. Madrid: Universidad Autónoma de Madrid. Retrieved from http://www.lllf.uam.es/ESP/Info Corlec.html

Martín Zorraquino, María Antonia y Portolés Lazaro, J. (1999). Los Marcadores del discurso. In Gramática descriptiva de la lengua española. (pp. 4051-4213).

Martínez Celdrán, E., \& Fernández Planas, A. M. (2007). Análisis espectrográfico de los sonidos del habla. Barcelona: Ariel.

Pons Bordería, S. (2014). El siglo XX como diacronía: intuición y compobación en el caso de "o sea." RILCE: Revista de Filología Hispánica, 30(3), 985-1016.

Schiffrin, D. (1987). Discourse Markers. Cambridge: Cambridge University Press. https://doi.org/10.1017/CBO9780511611841

Sohn, S. (2010). The role of frequency and prosody in the grammaticalization of Korean -canh-. In A. Van linden, J. Verstraete, \& K. Davidse (Eds.), Formal Evidence in Grammaticalization Research (pp. 245-273). Amsterdam: John Benjamins Publishing Company.

Tabor, W., \& Tragott, E. (1998). Structural Scope Expansion and Grammaticalization. In A. G. Ramat \& P. J. Hopper (Eds.), The Limits of Grammaticalization (pp. 229-272). Amsterdam: John Benjamins Publishing Company. https://doi.org/http://dx.doi.org/10.1075/tsl.37.11tab

Traugott, E. (1995). The role of the development of discourse markers in a theory of grammaticalization. In INTERNATIONAL CONFERENCE ON HISTORICAL LINGUISTICS 12 (pp. 1-25). Manchester.

Wichmann, A. (2011). Grammaticalization and prosody. In B. Heine \& H. Narrog (Eds.), The Oxford Handbook of Grammaticalization (pp. 331-341). Oxford: Oxford University Press. https://doi.org/10.1093/oxfordhb/9780199586783.013.0026

Wichmann, A., Dehé, N., \& Barth-Weingarten, D. (2009). Where Prosody Meets Pragmatics: Research at the Interface. Where Prosody Meets Pragmatics. Brill. 


\section{no normas}

¿Se puede determinar el grado de gramaticalización de los marcadores del discurso a través de la prosodia? | Maria Estellés

Wichmann, A., Simon-Vandenbergen, A., \& Aijmer, K. (2010). How prosody reflects semantic change: A synchronic case study of of course. In K. D. Hubert Cuyckens \& L. Vandelanotte (Eds.), Subjectification, intersubjectification and grammaticalization (pp. 103-154). Berlin: Mouton de Gruyter. 